\title{
Eye movements, the perceptual span, and reading speed
}

\author{
Keith Rayner, Timothy J. Slattery, and Nathalie N. Bélanger \\ University of California, San Diego, La Jolla, California
}

\begin{abstract}
The perceptual span or region of effective vision during eye fixations in reading was examined as a function of reading speed (fast readers were compared with slow readers), font characteristics (fixed width vs. proportional width), and intraword spacing (normal or reduced). The main findings were that fast readers (reading at about $330 \mathrm{wpm}$ ) had a larger perceptual span than did slow readers (reading about $200 \mathrm{wpm}$ ) and that the span was not affected by whether or not the text was fixed width or proportional width. In addition, there were interesting font and intraword spacing effects that have important implications for the optimal use of space in a line of text.
\end{abstract}

One of the most robust findings in research on the process of reading is that the region from which readers obtain useful information (i.e., the perceptual span) is rather limited. That is, the perceptual span for skilled readers of alphabetic writing systems consists of three to four letters to the left of fixation (or the beginning of the currently fixated word) and 14 or 15 letter spaces to the right of fixation (see Rayner, 1998, 2009, for reviews). Evidence for this comes from studies utilizing the gaze-contingent moving window paradigm developed by McConkie and Rayner (1975; see also Rayner \& Bertera, 1979), in which the amount of information available to the reader is controlled on each eye fixation. That the asymmetry of the span is a function of attention is evident from the finding that it is reversed for readers of Hebrew (Pollatsek, Bolozky, Well, \& Rayner, 1981), who obtain more information from the left of fixation than from the right. It is also clear that the span is not simply the result of acuity limitations, since Miellet, O’Donnell, and Sereno (2009) demonstrated that the span to the right of fixation remained 14 or 15 letter spaces when they used a parafoveal magnification technique in which letters on each fixation became increasingly larger further from fixation (to offset acuity limitations).

Quite surprisingly, despite a considerable amount of research using the gaze-contingent moving window, an important issue remains largely unresolved. Specifically, does the size of the perceptual span vary as a function of reading speed? Do fast readers have a larger perceptual span than slow readers? Jackson and McClelland (1975) concluded that the area from which a reader can obtain useful visual information was approximately the same for fast and slow readers. A number of other studies likewise concluded that low-level perceptual processing (in terms of how far from fixation letter information can be obtained) does not differentiate slow and fast readers (see Rayner \& Pollatsek, 1989, for an overview). But these studies did not use the moving window paradigm.

Furthermore, research using the moving window paradigm does not provide a consistent picture with respect to the question. For example, Underwood and Zola (1986) used a variation of the moving window paradigm (in which on selected fixations, letters in the display were replaced by other letters) to investigate the span of letter recognition ${ }^{1}$ for good and poor readers. They found that both good and poor fifth-grade readers acquire letter information from a region extending from two letters to the left of fixation to about six or seven letters to the right. Not surprisingly (see Rayner, 1998), the poor readers had longer fixations overall than did the good readers, but the disruption caused by the letter replacement was similar for the two groups. On the other hand, in rather direct contrast to Underwood and Zola, using a similar manipulation Häikiö, Bertram, Hyönä, and Neimi (2009) found that the span of letter identity was smaller for slower readers than for fast readers. Other research using the moving window paradigm has found that beginning readers (Häikiö et al., 2009; Rayner, 1986), dyslexic readers (Rayner, Murphy, Henderson, \& Pollatsek, 1989), and older readers (Rayner, Castelhano, \& Yang, 2009) have smaller perceptual spans than do college-age readers. But slow readers are not beginning readers, dyslexic readers, or older readers. They are skilled readers who read with perfectly normal comprehension, but at a slower rate than some of their peers.

On the basis of prior work, it seemed quite possible that in a moving window study with fast and slow readers, there could either be (1) no difference between the two groups in terms of when reading performance would reach asymptote as a function of window size or (2) a difference wherein slow readers would reach asymptote with smaller windows than would fast readers. The first prediction would be consistent with the position that fast

K. Rayner, krayner@ucsd.edu 
and slow readers extract useful information from the same area of text during each fixation but that slower readers require more time to do so. The second prediction would be consistent with the view that slower readers require more resources to encode and process the fixated word, leading to diminished resources for the processing of parafoveal information. The first prediction would yield a main effect of reading speed but no interaction with window size, whereas the second prediction would yield an interaction between reading speed and window size.

A secondary issue we addressed was whether font/ typographical properties have an effect on the size of the perceptual span. In most research on eye movements during reading and prior research using the moving window paradigm, a fixed-width font such as Courier New has been used. There are numerous advantages to using such fonts. First, since every letter has the same width in these fonts, controlling the number of letters in a word or region also controls for the size of the region in terms of visual angle. Second, it is trivial to construct masks for words that can be used in gaze-contingent display change experiments, such as the moving window and/or boundary change (Rayner, 1975) paradigms, since any letter can be used to mask any other. This is not true for proportionalwidth fonts, since many letters will not have a suitable masking letter (a letter with the same number of horizontal pixels). Thus, prior display change studies have been conducted only with fixed-width fonts in order to avoid these problems. ${ }^{2}$ However, readers do not typically read text with fixed-width fonts but, rather, with proportionalwidth fonts. In the present study, we examined the perceptual span using both fixed- (Consolas) and proportional(Georgia) width fonts to determine whether the span is larger for the Georgia font, since readers are more familiar with proportional-width fonts. For the proportional-width font, we implemented the moving window paradigm by creating a unique mask for every word in which the intraletter spacing of the mask was adjusted such that the mask would have the same number of horizontal pixels as the target word. This allowed us to use the same masking letters with both fonts.

Finally, we explored what factors influence the optimal use of the space within a line for a given amount of text. More specifically, when the number of letters on a line and the horizontal size of the line are held constant, what is the best way to use the available space? We investigated this by manipulating whether or not the spacing between letters within a word was normal or reduced by $10 \%$. Note that by removing space between the letters within a word while holding the number of words and the size of the line constant, we necessarily had to add space between the words in this condition. Therefore, the space that was removed between the letters within a word was added to the space after the word, such that the first character of the next word always started at the same location regardless of spacing condition (see Figure 1). This procedure had the added benefit that, across these two spacing conditions, parafoveal processing of the upcoming words in the reduced letter spacing condition would not be confounded with the distance between the beginnings of words. Decreasing the space between letters might slow down reading, due to difficulties associated with encoding the fixated word. This, in turn, may result in decreased processing of parafoveal information, which would be evident in the present experiment. However, it also seemed possible that decreasing letter spacing may increase reading speed, due to the resulting additional space between words, which may assist with word demarcation and oculomotor programming of saccades.

\section{METHOD}

\section{Subjects}

Thirty-two undergraduate students at the University of California, San Diego, participated for course credit. They had either normal uncorrected vision or corrected-to-normal vision, and they were all naive concerning the purpose of the experiment. They were divided into two groups on the basis of their reading speed: fast readers (reading over $258 \mathrm{wpm}$, with an average reading rate of $337 \mathrm{wpm}$

\section{Example of the fonts used with the spacing manipulations}

Richard kicked his football through the goal for the extra point.

Richard kicked his football through the goal for the extra point.

Consolas reduced spacing

Consolas normal spacing

Richard kicked his football through the goal for the extra point.

Richard kicked his football through the goal for the extra point.

\section{Example of rightward window size of two words (asterisk represents fixation point) \\ Richard kicked klr taafdoii fksanyk fke yaoi tas fke cvfso qaluf. \\ Richard kicked klr taafdoii fksanyk fkc yaoi tas fkc cvfso qaluf.}

Richard kicked klr taafdoii flksanyk fkc yaoi tas fkc cvfso qaluf.

Richard kicked klr taafdoii fksanyk fkc yaoi tas fkc cvfso qaluf.
Georgia reduced spacing

Georgia normal spacing

Consolas reduced spacing

Consolas normal spacing

Georgia reduced spacing

Georgia normal spacing

Figure 1. Example of stimulus sentences without a window and with a two-word window. The asterisk represents a fixation point in the bottom two examples. 
with normally spaced fonts) and slow readers (reading less than $258 \mathrm{wpm}$, with an average reading rate of $207 \mathrm{wpm}$ with normally spaced fonts).

\section{Apparatus}

Eye movements were recorded via an SR Research Ltd. Eyelink 1000 eyetracker, with spatial resolution of less than $0.04^{\circ}$, which recorded the position of the reader's eye every half millisecond. Subjects were seated $60 \mathrm{~cm}$ away from a 21-in. Sony Trinitron GDMC520K CRT monitor (with a refresh rate of $120 \mathrm{~Hz}$ ) on which the stimuli were presented. Head movements were minimized with chin- and headrests. Although viewing was binocular, eye movements were recorded from the right eye.

\section{Design and Procedure}

There were four different window conditions: one word ( $1 \mathrm{~W}$; the currently fixated word was visible), two words ( $2 \mathrm{~W}$; the fixated word and the word to the right were both visible), or three words ( $3 \mathrm{~W}$; the fixated word and two words to the right were visible). For all of these conditions, the word immediately to the left of fixation was also visible. There was also a full-line or no-window (NW) control condition in which all the words were visible. Letters outside of the window were replaced by a unique mask for every word, in which the intraletter spacing of the mask was adjusted such that the mask had the same number of horizontal pixels as the target word. This allowed us to use the same masking letters with both fonts. The sentences appeared in either Consolas or Georgia font with either normal letter spacing or $10 \%$ reduction. An example sentence in each font and spacing condition is presented in Figure 1.

At the start of the experiment, the subjects completed a calibration procedure by fixating on three points randomly presented across the horizontal midline of the video monitor. At the start of each trial, a black square (15 pixels wide) appeared on the left side of the monitor. The left edge of this square coincided with the left side of the first letter in the upcoming sentence. The sentence replaced this square on the screen once a stable fixation was detected. Sentences were presented as black letters on a white background in 12-point Consolas or Georgia font. The Consolas font yielded 3.1 letters per degree of visual angle in the normal spacing conditions and 3.4 letters in the reduced letter spacing condition, and the Georgia font yielded 3.4 and 3.7 letters per degree, respectively. The subjects were instructed to read silently for comprehension and to press a button on a keypad when they finished reading. A Latin square counterbalancing procedure ensured than an equal number of items was seen in each condition by every subject, and across all the subjects, each item was seen an equal number of times in each condition. Order of presentation was randomized for each subject. The first eight trials were practice, to get the subjects accustomed to the procedure. Comprehension questions were asked after $39 \%$ of the trials. The two groups did not differ, since the slow and fast readers scored $89 \%$ and $88 \%$ correct, respectively $(t<1)$.

\section{Materials}

Following the practice sentences, the subjects read 160 experimental sentences (10 in each of the 16 experimental conditions). On average, these sentences contained 11.1 words and were 60.8 letters long (including interword spaces). The average length of a word was 4.6 letters. The average size of the rightward window (including interword spaces) was 5.6, 10.2, and 14.9 letter spaces in the $1 \mathrm{~W}$, $2 \mathrm{~W}$, and $3 \mathrm{~W}$ windows, respectively.

\section{RESULTS}

Fixations shorter than $80 \mathrm{msec}$ that were within one letter of another fixation were combined with that fixation $(0.2 \%$ of the fixations); all other fixations less than $80 \mathrm{msec}$ were eliminated (2.4\% of the fixations). Trials on which there was more than one blink during reading were removed prior to analysis ( $2.1 \%$ of the trials), as were trials in which the reading speed (wpm) was $3 S D$ above or below the subject's mean for a given window size $(0.8 \%$ of the trials). Trial exclusion affected all conditions similarly $(F<1)$.

The most diagnostic measure in analyzing data from moving window experiments is the reading rate (wpm) as a function of window size. We will first report those data (see Figure 2), followed by analyses of (1) average fixation duration, (2) number of forward fixations, (3) number of regressive fixations, and (4) average forward saccade length. ${ }^{3}$ For each of these variables, separate 2 (reading group: fast or slow) $\times 4$ (window size: $1 \mathrm{~W}, 2 \mathrm{~W}, 3 \mathrm{~W}$, or NW) $\times 2$ (font: Consolas or Georgia) $\times 2$ (spacing: normal or reduced) ANOVAs were conducted. Table 1 shows the data from all conditions for these variables. For most of these analyses, the group variable was significant, but this is not surprising given that the subjects were identified with the two groups as a function of their reading speed in the NW condition. What is more interesting is the extent to which there were interactions of group with other variables.

\section{Reading Rate}

In addition to the obvious main effect of group $\left[F(1,30)=44.65, p<.0001, \eta_{\mathrm{p}}^{2}=.60\right]$, there were also main effects of spacing $\left[F(1,30)=4.43, p<.04, \eta_{\mathrm{p}}^{2}=\right.$ $.13]$, with reduced spacing yielding faster reading rates than did normal spacing, and window size $[F(3,90)=$ $\left.110.23, p<.0001, \eta_{\mathrm{p}}^{2}=.79\right]$. More interestingly, there was an interaction of group and window size $[F(3,90)=$ $12.37, p<.0001, \eta_{\mathrm{p}}^{2}=.29$ ], which is apparent in Figure 2 and is such that the slow readers reached asymptote in reading rate early (with a window size of $2 \mathrm{~W}$ ), whereas the fast readers continued to improve as window size increased. Post hoc $t$ tests revealed that for the slow readers, the $1 \mathrm{~W}$ window differed from the $2 \mathrm{~W}$ window $(p<.01)$, but the $2 \mathrm{~W}, 3 \mathrm{~W}$, and NW conditions did not differ from each other $(p s>.10)$. For the fast readers, all window sizes were significantly different from each other $(p$ s $<$ .05 ). There was no significant effect of font, nor were there interactions associated with either font or spacing.

\section{Fixation Duration}

There was a main effect of group $[F(1,30)=9.52, p<$ $\left..04, \eta_{\mathrm{p}}^{2}=.24\right]$, with slow readers having longer fixations than did fast readers, and a main effect of window size $\left[F(3,90)=38.52, p<.0001, \eta_{\mathrm{p}}^{2}=.56\right]$. However, there were also main effects of font $[F(1,30)=213.66, p<$ $\left..0001, \eta_{\mathrm{p}}^{2}=.87\right]$, with Georgia yielding longer fixations than did Consolas, and of spacing $[F(1,30)=27.59, p<$ $\left..0001, \eta_{\mathrm{p}}^{2}=.48\right]$, with reduced spacing actually leading to shorter fixations than did normal spacing. Also, there was a font $\times$ spacing interaction $[F(1,30)=11.32, p<.002$, $\left.\eta_{\mathrm{p}}^{2}=.27\right]$, with readers of Georgia benefiting more from reduced spacing. Finally, there was a group $\times$ spacing $\times$ window size interaction $\left[F(3,90)=3.69, p<.015, \eta_{\mathrm{p}}^{2}=\right.$ $.11]$, which was due to a particularly flat slope across the window size conditions for the slow readers with normal spacing. 


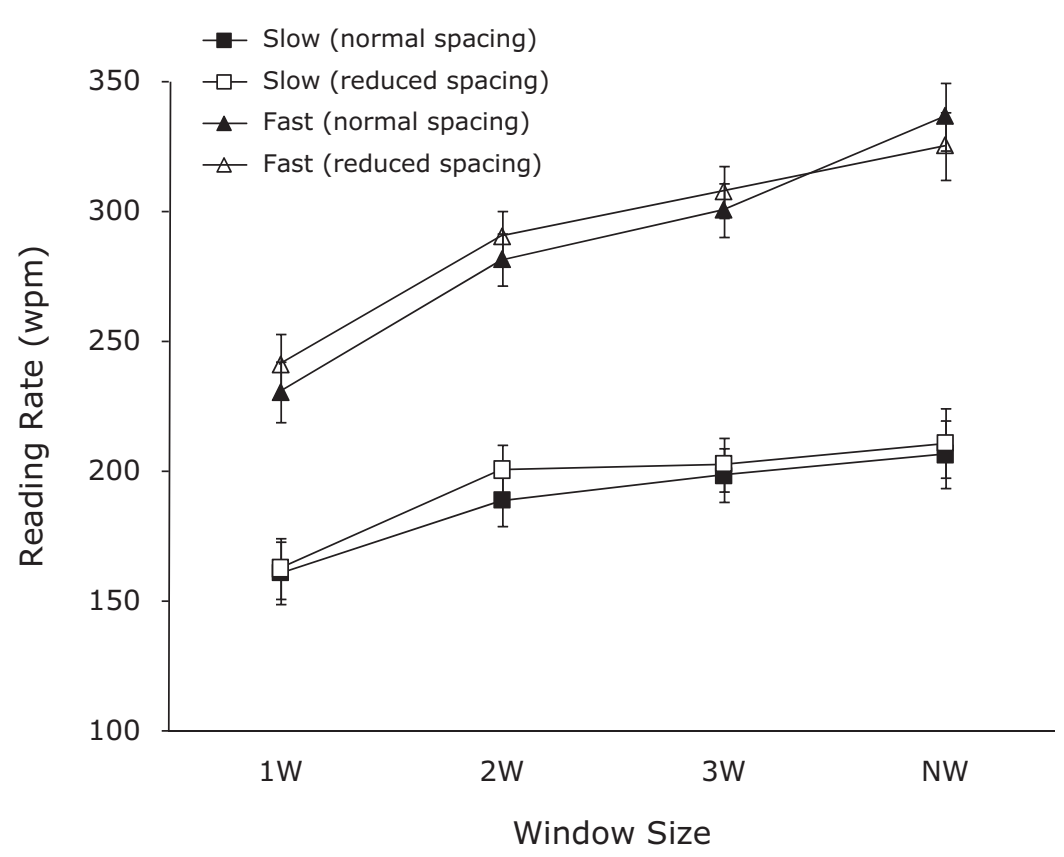

Figure 2. Reading rate (words per minute) as a function of window size (1W, one word; $2 \mathrm{~W}$, two words; $3 \mathrm{~W}$, three words; $\mathrm{NW}$, no window) and spacing for the fast and slow readers. Error bars indicate the standard errors of the means.

\section{Number of Forward Fixations}

There were main effects of group $[F(1,30)=29.25$, $p<.0001, \eta_{\mathrm{p}}^{2}=.49$ ], with slow readers having more fixations than did fast readers, and of window size $[F(3,90)=$ $\left.81.59, p<.0001, \eta_{\mathrm{p}}^{2}=.73\right]$. There was also a main effect of font $\left[F(1,30)=62.04, p<.0001, \eta_{\mathrm{p}}^{2}=.67\right]$, with Consolas yielding more fixations than did Georgia. It is noteworthy that this effect is just the opposite of what we found in fixation durations. There was also a main effect of spacing $\left[F(1,30)=14.80, p<.001, \eta_{\mathrm{p}}^{2}=.33\right]$, with fewer fixations for reduced spacing. Finally, there was an interaction of group and spacing $[F(1,30)=6.99, p<$ $\left..01, \eta_{\mathrm{p}}^{2}=.19\right]$, with the benefit for reduced spacing being larger for the slow readers.

Table 1

Means for Various Eye Movement Measures (With Standard Errors)

\begin{tabular}{|c|c|c|c|c|c|c|c|c|c|c|c|c|c|c|c|c|c|}
\hline \multirow[b]{4}{*}{ Measure } & \multirow[b]{4}{*}{ Spacing } & \multicolumn{16}{|c|}{ Font } \\
\hline & & \multicolumn{8}{|c|}{ Consolas } & \multicolumn{8}{|c|}{ Georgia } \\
\hline & & \multicolumn{2}{|c|}{$\begin{array}{c}1 \mathrm{~W} \\
\text { Window }\end{array}$} & \multicolumn{2}{|c|}{$\begin{array}{c}2 \mathrm{~W} \\
\text { Window }\end{array}$} & \multicolumn{2}{|c|}{$\begin{array}{c}3 \mathrm{~W} \\
\text { Window }\end{array}$} & \multicolumn{2}{|c|}{ NW } & \multicolumn{2}{|c|}{$\begin{array}{c}1 \mathrm{~W} \\
\text { Window }\end{array}$} & \multicolumn{2}{|c|}{$\begin{array}{c}2 \mathrm{~W} \\
\text { Window }\end{array}$} & \multicolumn{2}{|c|}{$\begin{array}{c}3 \mathrm{~W} \\
\text { Window }\end{array}$} & \multicolumn{2}{|c|}{ NW } \\
\hline & & $M$ & $S E$ & $M$ & $S E$ & $M$ & $S E$ & $M$ & $S E$ & $M$ & $S E$ & $M$ & $S E$ & $M$ & $S E$ & $M$ & $S E$ \\
\hline \multicolumn{18}{|c|}{ Slower Readers } \\
\hline \multirow[t]{2}{*}{ MFD } & Normal & 253 & 8.2 & 242 & 5.8 & 242 & 7.5 & 236 & 6.0 & 266 & 7.8 & 254 & 6.9 & 257 & 7.1 & 255 & 6.7 \\
\hline & Reduced & 255 & 7.6 & 238 & 6.6 & 236 & 6.1 & 237 & 7.2 & 264 & 8.6 & 250 & 6.8 & 246 & 5.9 & 241 & 6.0 \\
\hline \multirow[t]{2}{*}{$\# \mathrm{FF}$} & Normal & 14.2 & .49 & 12.5 & .40 & 12.2 & .36 & 11.9 & .52 & 13.8 & .44 & 12.1 & .38 & 11.4 & .40 & 10.8 & .31 \\
\hline & Reduced & 13.8 & .63 & 12.1 & .37 & 11.6 & .35 & 11.6 & .35 & 13.4 & .52 & 11.4 & .39 & 11.1 & .37 & 10.7 & .34 \\
\hline \multirow[t]{2}{*}{ \#RF } & Normal & 3.7 & .36 & 3.0 & .31 & 2.9 & .23 & 2.8 & .33 & 3.6 & .35 & 3.3 & .28 & 2.8 & .25 & 2.4 & .23 \\
\hline & Reduced & 3.9 & .32 & 2.9 & .22 & 3.0 & .27 & 2.9 & .24 & 3.6 & .30 & 2.9 & .29 & 2.9 & .28 & 2.8 & .25 \\
\hline \multirow[t]{2}{*}{ FSL } & Normal & 6.2 & .37 & 7.0 & .34 & 7.0 & .36 & 7.0 & .34 & 6.5 & .34 & 7.4 & .38 & 7.6 & .43 & 7.6 & .39 \\
\hline & Reduced & 6.4 & .35 & 6.9 & .42 & 7.3 & .37 & 7.1 & .31 & 6.8 & .37 & 7.5 & .38 & 7.6 & .39 & 7.8 & .34 \\
\hline \multicolumn{18}{|c|}{ Faster Readers } \\
\hline \multirow[t]{2}{*}{ MFD } & Normal & 231 & 8.2 & 214 & 5.8 & 210 & 7.5 & 205 & 6.0 & 244 & 7.8 & 229 & 6.9 & 226 & 7.1 & 216 & 6.7 \\
\hline & Reduced & 224 & 7.6 & 212 & 6.6 & 210 & 6.1 & 208 & 7.2 & 237 & 8.6 & 223 & 6.8 & 221 & 5.9 & 213 & 6.0 \\
\hline \multirow[t]{2}{*}{$\# \mathrm{FF}$} & Normal & 11.3 & .49 & 9.7 & .40 & 9.3 & .36 & 8.9 & .52 & 10.6 & .44 & 9.0 & .38 & 8.6 & .40 & 8.4 & .31 \\
\hline & Reduced & 10.9 & .63 & 9.3 & .37 & 9.2 & .36 & 8.9 & .35 & 10.4 & .52 & 9.2 & .39 & 8.5 & .37 & 8.6 & .34 \\
\hline \multirow[t]{2}{*}{ \#RF } & Normal & 2.6 & .28 & 2.1 & .31 & 1.9 & .23 & 1.4 & .33 & 2.2 & .35 & 1.7 & .28 & 1.6 & .25 & 1.3 & .23 \\
\hline & Reduced & 2.5 & .32 & 1.9 & .22 & 1.9 & .27 & 1.7 & .24 & 2.2 & .30 & 2.0 & .29 & 1.8 & .28 & 1.8 & .25 \\
\hline \multirow[t]{2}{*}{ FSL } & Normal & 7.4 & .48 & 8.2 & .44 & 8.7 & .46 & 8.7 & .43 & 7.8 & .42 & 8.8 & .47 & 9.4 & .55 & 9.3 & .51 \\
\hline & Reduced & 7.6 & .46 & 8.5 & .57 & 8.9 & .47 & 8.8 & .40 & 8.1 & .46 & 9.2 & .48 & 9.5 & .49 & 9.6 & .46 \\
\hline
\end{tabular}

Note-1W, one word; $2 \mathrm{~W}$, two words; $3 \mathrm{~W}$, three words; NW, no window; MFD, mean fixation duration (in milliseconds); \#FF, number of forward fixations; \#RF, number of regressive fixations; FSL, mean forward saccade length in number of letter spaces. 


\section{Number of Regressive Fixations}

There were main effects of group $[F(1,30)=13.25, p<$ $\left..001, \eta_{\mathrm{p}}^{2}=.31\right]$, with slow readers having more regressive fixations than did fast readers, window size $[F(3,90)=$ $\left.25.78, p<.0001, \eta_{\mathrm{p}}^{2}=.46\right]$, and font $[F(1,30)=4.29$, $p<.047, \eta_{\mathrm{p}}^{2}=.13$ ], with Consolas yielding more regressions. There was also a marginally significant main effect of spacing with more regressions for reduced spacing $\left[F(1,30)=3.39, p<.076, \eta_{\mathrm{p}}^{2}=.10\right]$.

\section{Saccade Length}

There was a main effect of group $[F(1,30)=9.47, p<$ $\left..004, \eta_{\mathrm{p}}^{2}=.24\right]$, with slow readers making shorter saccades than did fast readers. There were also main effects of font $\left[F(1,30)=110.81, p<.0001, \eta_{\mathrm{p}}^{2}=.78\right]$, with Consolas yielding shorter saccades than did Georgia, and of spacing $\left[F(1,30)=15.98, p<.0001, \eta_{\mathrm{p}}^{2}=.35\right]$, with shorter saccades for reading with normal spacing. There was also a main effect of window size $[F(3,90)=82.49, p<.0001$, $\left.\eta_{\mathrm{p}}^{2}=.73\right]$. Finally, the group $\times$ window size interaction was also significant $\left[F(3,90)=9.70, p<.004, \eta_{\mathrm{p}}^{2}=.24\right]$. Post hoc $t$ tests revealed that for the slow readers, the $1 \mathrm{~W}$ window differed from the $2 \mathrm{~W}$ window $(p<.01)$, but the $2 \mathrm{~W}, 3 \mathrm{~W}$, and $\mathrm{NW}$ conditions did not differ from each other ( $p \mathrm{~s}>.10)$, indicating again that the slow readers asymptoted with a $2 \mathrm{~W}$ window. For the fast readers, the $1 \mathrm{~W}$ condition differed from the $2 \mathrm{~W}$ condition $(p<.01)$, and the $2 \mathrm{~W}$ condition differed from the $3 \mathrm{~W}$ condition $(p<.01)$, but the $3 \mathrm{~W}$ window did not differ from the NW condition $(p>.10)$, indicating that fast readers, contrary to the slow readers, reached asymptote with a $3 \mathrm{~W}$ window.

\section{DISCUSSION}

A number of interesting findings emerged from the present study. First, slow readers had a smaller perceptual span than did fast readers. As we noted at the outset, whether or not there are differences in the perceptual span between fast and slow readers in the moving window paradigm was not apparent, although our results are consistent with findings reported by Häikiö et al. (2009) on the size of the letter identity span. Given that it is fairly well established that fast and slow readers do not differ in their ability to identify words/letters presented at different distances from fixation (Jackson \& McClelland, 1975; see Rayner \& Pollatsek, 1989, for a review), the best explanation for this result is that slow readers use more processing resources to encode and understand the fixated word than do fast readers. This explanation is also consistent with the finding that young children (Häikiö et al., 2009; Rayner, 1986), dyslexic readers (Rayner et al., 1989), and older readers (Rayner et al., 2009) all have smaller perceptual spans than do skilled college-age readers. In all of these cases, the difference has been attributed to difficulty processing the fixated word, leading to less processing of information to the right of fixation.

It is interesting to note that in terms of reading rate (but not saccade size), fast readers did not reach asymptotic performance with the $3 \mathrm{~W}$ window. As we noted earlier, a $3 \mathrm{~W}$ window corresponded to an average of 14.9 letter spaces available to the right of fixation. Thus, according to prior research (Rayner, Well, Pollatsek, \& Bertera, 1982), a $3 \mathrm{~W}$ window should, in principle, be large enough that all useful information can be obtained. However, it is important to keep in mind that 14.9 letter spaces is an average, and depending on the length of words to the right of fixation, the window (in terms of number of letters) could be as small as 8-11 letter spaces. Thus, on some fixations, a $3 \mathrm{~W}$ window would not be large enough for fast readers to process the text normally but would be large enough for slow readers. This accounts for why the fast readers still showed improvement in reading rate for the NW condition, as compared with the $3 \mathrm{~W}$ condition.

Second, the size of the perceptual span did not differ between a fixed-width and a proportional spacing font. This result validates prior research using the moving window paradigm that has used only fixed-width fonts. In addition, the type of font did not influence reading rate, but there was an interesting trade-off between fixation duration and number of fixations. Specifically, the Consolas (fixedwidth) font yielded more forward fixations than did the Georgia (proportional) font, but fixation durations were shorter for the Consolas font than for the Georgia font, leading to no overall difference in reading rate. A likely reason for these trade-offs is that Consolas letters are wider than those in Georgia font. This may make the encoding of the foveal letters more efficient (due to their larger size) but would allow fewer letters to be located within the fovea at any given time, thereby requiring more fixations for complete encoding. This notion is supported by the size of forward saccades, which traversed fewer letters with the wider Consolas font. However, if forward saccade length is measured in visual angle instead of number of letter spaces, the difference between the two fonts is negligible $\left(2.33^{\circ}\right.$ and $2.30^{\circ}$, respectively). Therefore, although the eyes were moving a similar absolute distance in both fonts, this indicates that more letters were processed with each fixation in the smaller proportional-width Georgia font.

Finally, there was an interesting effect of spacing in which reduced letter spacing (intraword spacing) actually led to faster reading rates (as well as shorter and fewer forward fixations) than did the normal spacing condition. We suspect that this effect is due to the combination of intraword and interword spacing (spacing between words), with much of the benefit being due to increased interword spacing. That is, it may be the case that reducing the spacing between letters within a word actually hinders word identification to some extent, due to increased lateral masking of the word-interior letters, but if so, this effect is outweighed by benefits to reading from the inclusion of additional space between words, which decreases lateral masking of exterior word letters and provides for superior boundary demarcation. Such benefits from additional interword spacing have been reported in previous studies (Drieghe, Brysbasert, \& Desmet, 2005; cf. Paterson \& Jordan, 2010) and may be due to improved targeting of saccades to optimal locations.

An interesting question with regard to text layout is how to make optimal use of the space available. There are two important results from the present study that indicate 
that words can be identified without much, if any, disruption when they occupy a smaller visual angle. First, there were no significant differences in reading rate between the Georgia and Consolas fonts, despite the fact that the letters in the Georgia font take up less horizontal space than do those of Consolas. Second, for both fonts, there was an increase in reading rate when spacing between letters was reduced by $10 \%$, so long as this space was added between words. The results of the present research are also consistent with other recent research demonstrating either subtle but significant effects (Slattery \& Rayner, 2010) or large effects (Rayner, Reichle, Stroud, Williams, \& Pollatsek, 2006) of font, depending on how difficult the fonts are to process.

\section{AUTHOR NOTE}

The research reported here was supported by a grant from the Microsoft Corporation to the first and second authors. Preparation of the article was further supported by Grant HD26765 from the National Institutes of Health and the Atkinson Research Fund. The third author was supported by a fellowship from the Fonds Québécois de la Recherche sur la Société et la Culture. We thank Simon Liversedge and an anonymous reviewer for helpful comments on an earlier draft. Correspondence concerning this article should be addressed to K. Rayner, Department of Psychology, University of California, San Diego, La Jolla, CA 92093 (e-mail: krayner@ucsd.edu).

Note-Accepted by Cathleen M. Moore's editorial team.

\section{REFERENCES}

Drieghe, D., Brysbaert, M., \& Desmet, T. (2005). Parafoveal-onfoveal effects on eye movements in reading: Does an extra space make a difference? Vision Research, 45, 1693-1706. doi:10.1016/j.visres .2005 .01 .010

Häıkiö, T., Bertram, R., HyönÄ, J., \& NeImi, P. (2009). Development of the letter identity span in reading: Evidence from the eye movement moving window paradigm. Journal of Experimental Child Psychology, 102, 167-181. doi:10.1016/j.jecp.2008.04.002

JACKSON, M. D., \& MCClelland, J. L. (1975). Sensory and cognitive determinants of reading speed. Journal of Verbal Learning \& Verbal Behavior, 19, 565-574. doi:10.1016/S0022-5371(75)80044-2

McConkie, G. W., \& Rayner, K. (1975). The span of the effective stimulus during a fixation in reading. Perception \& Psychophysics, 17, 578-586.

Miellet, S., O’Donnell, P. J., \& Sereno, S. C. (2009). Parafoveal magnification: Visual acuity does not modulate the perceptual span in reading. Psychological Science, 20, 721-728. doi:10.1111/j.1467 $-9280.2009 .02364 . x$

Paterson, K. B., \& Jordan, T. R. (2010). Effects of increased letter spacing on word identification and eye guidance during reading. Memory \& Cognition, 38, 502-512. doi:10.3758/MC.38.4.502
Pollatsek, A., Bolozky, S., Well, A. D., \& Rayner, K. (1981). Asymmetries in the perceptual span for Israeli readers. Brain \& Language, 14, 174-180. doi:10.1016/0093-934X(81)90073-0

RAYNER, K. (1975). The perceptual span and peripheral cues in reading. Cognitive Psychology, 7, 65-81. doi:10.1016/0010-0285(75)90005-5

RAYNER, K. (1986). Eye movements and the perceptual span in beginning and skilled readers. Journal of Experimental Child Psychology, 41, 211-236. doi:10.1016/0022-0965(86)90037-8

RAYNER, K. (1998). Eye movements in reading and information processing: 20 years of research. Psychological Bulletin, 124, 372-422. doi:10.1037/0033-2909.124.3.372

RAYNER, K. (2009). Eye movements and attention in reading, scene perception, and visual search. Quarterly Journal of Experimental Psychology, 62, 1457-1506. doi:10.1080/17470210902816461

Rayner, K., \& Bertera, J. H. (1979). Reading without a fovea. Science, 206, 468-469. doi:10.1126/science.504987

Rayner, K., Castelhano, M. S., \& Yang, J. (2009). Eye movements and the perceptual span in older and younger readers. Psychology \& Aging, 24, 755-760. doi:10.1037/a0014300

Rayner, K., Murphy, L. A., Henderson, J. M., \& Pollatsek, A. (1989). Selective attentional dyslexia. Cognitive Neuropsychology, 6, 357-378. doi:10.1080/02643298908253288

Rayner, K., \& Pollatsek, A. (1989). The psychology of reading. Englewood Cliffs, NJ: Prentice Hall.

Rayner, K., Reichle, E. D., Stroud, M. J., Williams, C. C., \& PolLATSEK, A. (2006). The effect of word frequency, word predictability, and font difficulty on the eye movements of young and older readers. Psychology \& Aging, 21, 448-465. doi:10.1037/0882-7974 .21 .3 .448

Rayner, K., Well, A. D., Pollatsek, A., \& Bertera, J. H. (1982). The availability of useful information to the right of fixation in reading. Perception \& Psychophysics, 31, 537-550.

Slattery, T. J., \& Rayner, K. (2010). The influence of text legibility on eye movements during reading. Applied Cognitive Psychology, 24, 1129-1148.

Underwood, N. R., \& Zola, D. (1986). The span of letter recognition of good and poor readers. Reading Research Quarterly, 21, 6-19. doi: $10.2307 / 747956$

\section{NOTES}

1. The letter recognition span (or word identity span) differs from the perceptual span in that the former refers to the area from which readers obtain specific letter information, whereas the perceptual span includes not only specific letter information but also more gross information about letter features and spacing between words.

2. Fixed-width fonts have traditionally been used in moving window experiments because, if they are not, letters appear to jump around with each display change.

3. Average fixation durations for forward fixations and for regressive fixations were also analyzed but will not be discussed, since they yielded no additional useful information.

(Manuscript received April 19, 2010; revision accepted for publication July 17, 2010.) 